\title{
Review
}

\section{Differences in suicidal behavior in sexual and gender minority populations}

\author{
Amir Knaani ${ }^{1, *}$, Lucian Tatsa Laur ${ }^{1}$ \\ ${ }^{1}$ Department of Health and Well-Being, IDF Medical Corps, Israel Defense Forces, 5262000 Ramat Gan, Israel \\ *Correspondence: amir.knaani@gmail.com (Amir Knaani) \\ Submitted: 3 July 2021 Accepted: 26 August 2021 Available online: 15 September 2021 Published: 9 February 2022
}

\begin{abstract}
Suicide is a critical public-health issue that remains the leading cause of death among young adults aged 15 to 24 . In lesbian, gay, bisexual, transgender and queer (LGBTQ) populations the risk of suicidal thoughts and actions is significantly higher. The effect of natal sex vs. gender identity has not been studied enough as yet. In this study the PubMed-database was searched systematically for articles on the association between gender/sex differences and suicidality. Included were: meta-analyses, systematic and narrative reviews, firsthand observational studies and qualitative studies, published prior to 1 January 2021. Twenty-nine publications were found relevant, the majority on self-harm and suicide attempts and only few on death by suicide. Sexual (29.68\%-lifetime) and gender (46.65\%) minorities seem more likely to die by suicide than heterosexual/cisgender (14.57\%) people. At greatest risk are transgender (56.65\%) and bisexual (41.47\%) individuals. Most studies reported natal males to be more affected than natal females. The "gender paradox in suicide" does not exist among sex and gender minorities (SGMs), but differences in suicidal behavior exist between the various SGM groups. More research on suicidal behavior among these groups, especially longitudinal research, is necessary.
\end{abstract}

Keywords: Lesbian, gay, bisexual, transgender, queer (LGBTQ); Gender-non-conforming; Sexual minorities; Gender minorities; Sexual orientation; Suicidal ideation; Suicide attempt; Suicide plan; Non-suicidal self-injury

\section{Introduction}

Suicide, suicidal ideation (SI), suicide planning (SP), non-suicidal self-injury (NSSI) and suicide attempt (SA) are all major public health issues that can be prevented $[1,2]$. The annual rate of mortality by suicide amounts to about 800,000 people worldwide $[3,4]$. Suicide ranked tenth out of the top causes of death in the United States in 2015, and second among teenagers aged 14 to 18 . Seven percent of students in high school report attempting suicide.

Evidence suggests that sexual and gender minorities (SGMs) are more likely to attempt suicide than the heterosexual majority. Data from over 75 primary research studies conducted in several countries in Western Europe and in the United States - showing that SGM individuals are up to four times more likely to have attempted suicide than heterosexual people were combined into four systematic reviews and meta-analyses [5-8]. This led to the understanding worldwide that greater emphasis has to be placed on research and interventions designed to prevent suicide among SGMs $[8,9]$.

Lesbian, gay, bisexual, transgender, and queer ${ }^{1}$ (LGBTQ) individuals are at increased risk for several health conditions, including mental illness [10-12]. Health disparities among LGBTQ groups have got increased attention in recent years [13]. Suicidal behaviors are no exception [14-
17].

Nonetheless, several key issues of suicidal behavior among SGM remain somewhat vague. It is unclear whether male and female SGM individuals differ regarding suiciderelated outcomes. The data presented in this article may shed light on what the literature refers to as the "Gender Paradox", which is that males are three times more likely to die by suicide than females, although females attempt suicide three times more than males do. The word "gender" in this term may be confusing nowadays, as the term was coined at a time when "sex" and "gender" were used interchangeably in common language. This paradox remains consistent in all age groups [18]. In certain countries, the ratio of male to female deaths by suicide is $12: 1$ among older adults [19].

Gender affects patterns of socialization, exposure to stressors, and allocation of resources [20,21]. It also determines the nature of sexual identity, development, and expression [22]. For example, the gender paradox can be partially explained by males tending to have more access to lethal weapons, due to higher rates of males serving in military combat units. The relationship between (natal) sex differences and suicidality has been widely discussed in literature. This study attempts to demonstrate the impact on suicidality of differences in sexual orientation (SO) and gender identity.

\footnotetext{
${ }^{1}$ Although the letter Q in the acronym LGBTQ sometime stands both for "Queer" and for "Questioning", this article focused on the queer identity.
} 
Sexual identity influences the perceived and realized gender roles [23]. The cross-effects of sex, gender and sexual identity are often unpredictable [24,25]. Van Anders proposed the term gender/sex and the new "sexual configuration theory" approach, which takes into account not only one's natal sex or gender ideation, but also other variables, such as number of partners, external performances, fetishes etc. [26,27]. Gender/sex describes the inseparability of people's phenotypes, behaviours and biological characteristics, which are derived from both nature and nurture. The term gender/sex however, should be used with extreme caution, because it may negate the insights into these two terms gained from recent research, especially when dealing with transgender and gender non-conforming communities.

The question this study attempted to research and answer was: How does gender/sex moderate the risk for suicidal behavior among SGM populations?

\section{Methods}

A literature search of the PubMed database for the years 1970-2021 retrieved a total of 91 related articles, 29 of which were relevant to the research question. The current review is narrative rather than systematic in nature, summarizing findings described in the selected meta-analyses, narrative reviews, and other studies.

The information gathered from the database scan was imported into Endnote, version 20 for Macintosh. Each of the two authors searched the database for the following strings: "Lesbian/Gay/Bisexual/Transgender/LGBT/LGBTQ/GenderNon-Conforming/Sexual Minorities/Gender minorities/Sexual Orientation" and "Suicidal Ideation/Suicide Attempt/Suicide Plan/Suicide Ideation/Non suicidal self-harm".

The results included 91 articles. Those were further refined by examining the relevance of each individual article and keeping only those that the author deemed relevant. Next, the two authors compared their lists and kept only articles that appeared in both. This process resulted in 29 articles deemed relevant to the current study.

\section{Results}

\subsection{Suicides}

Studies dealing with death by suicide among SGMs are scarce. Since death charts don't register the deceased person's SO and gender identification, it is impossible to determine the rate of deaths by suicide among LGBTQ individuals.

In most studies, the SO of a deceased person can be concluded from data of two major sources: records of the national registry, in locations where same-sex marriage is officially allowed and reports of "psychological autopsies" conducted by family members and friends. The samples used in psychological autopsy studies are usually small in size and identify only a few suicide victims as belonging to a SO minority group [28].

According to data collected from the Danish national registry, suicide rates among registered same-sex partners were higher than those of married heterosexual individuals. Three relevant studies reported varying differences in those rates. In the first study, there was a medium-sized difference (combined, both men and women) [29]. The effect in the second study was significant only for men [30]. In a third study, however, the effect for men was medium, while for women it was strong [31].

The third study showed higher rates of suicide among homosexual couples who were known in public, compared to heterosexual cohabiting people (medium effect was found for men, while small effect was found for women). Among 85 men in the United States National Health and Nutrition Examination Survey (NHANES), no suicides were reported [32], but the study was underpowered, thus no reliable conclusions can be drawn [33]. The General Social Survey determined SGM status by taking into consideration a person's sexual behavior throughout her or his lifetime, and SGM men were not statistically different from other men but had lower suicide rates (medium effect), whereas SGM women had significantly higher rates (high effect) [34].

However, psychological autopsy studies in which control groups of living SGM individuals were compared with young SGM individuals who died by suicide showed the opposite $[35,36]$. Contrary to original reporting claiming no difference, later a significant effect was reported [33].

A recent study [37], analyzed data on suicide victims $(\mathrm{N}=123,289)$ from 18 states in the US that were included in the National Violent Death Reporting System from 2003 to 2014. Of those cases, $621(0.5 \%)$ were identified as LGBTQ individuals. LGBTQ people who died were found to be mostly gay men $(53.9 \%)$, followed by lesbian women $(28.0 \%)$, transgender (10.4\%) and bisexual (7.5\%) individuals. Among the deceased transgender people $21.5 \%$ were in the process of transitioning or were reported as unknown self-identified gender. Of the other transgender people who had died, $10.8 \%$ were registered as men while $67.7 \%$ were registered as women. Among the bisexual people 70.2\% were registered as males and $29.8 \%$ as females.

Findings suggest that compared to non-gay male decedents, a higher percentage of gay men who died by suicide had mental health issues, were treated for mental illness, indicated their intent to die by suicide, exhibited suicidal thoughts or plans, or had previously attempted suicide. Lesbian decedents were more likely to have a history of suicidal thoughts or plans, to have announced their intention to kill themselves, and to have attempted suicide before, compared to non-lesbian women. Lesbian and gay people reported more ongoing depression than non-lesbian or nongay people, with about half reporting depressive symptoms. In part, these differences are related to minority stress and 
discrimination experienced by lesbian and gay individuals $[38,39]$.

\subsection{Suicidal behavior and ideation}

SAs and NSSIs are more common in the LGBTQ community [40]. Past SA is the strongest predictor for death by suicide [41]. The rates of SA among LGBTQ individuals are much higher than in the non-LGBTQ population [42]. LGBTQ youth are 4-6 times more likely to perform a SA that requires medical treatment [40]. Other predictors for death by suicide include old age, male gender, unemployment, psychiatric disorders and NSSI history.

Thirty cross-sectional studies $(\mathrm{N}=21,201)$ of SGM adults revealed among the respondents of population surveys, an estimated lifetime prevalence of SAs of $11 \%$ for LGBTQ individuals and only 4\% for heterosexual people. It was much higher (20\%) for LGBTQ respondents of community surveys [5].

Caputi, Smith [43] conducted a study using the 2015 USA National Youth Risk Behavior Survey, which included 15,624 high-school students that reported their SO (male/female). Rates of bisexuality and of those still questioning their sexual identity were higher among females: $88.8 \%$ were self-identified as heterosexual $(93.1 \%$ $\mathrm{M} / 84.5 \% \mathrm{FM}), 2.0 \%$ as lesbian/gay $(2.0 \% \mathrm{M} / 2.0 \% \mathrm{FM})$, $6.0 \%$ as bisexual $(2.4 \mathrm{M} / 9.8 \% \mathrm{FM})$ and $3.2 \%$ as "questioning" (2.6\% M, 3.7\% FM). LGBTQ teens were 2.45 times more likely to seriously consider suicide without a specific plan, after confounder adjustments (40\% vs. 14.8\%; heterosexual). Compared to heterosexual people, the chance to LGBTQ teens to plan suicide was 2.59 times bigger $(34.9 \%$ vs. $11.9 \%$ ) and to attempt suicide 3.37 times bigger $(24.9 \%$ vs. $6.3 \%$ ). This pattern persisted in sub-group analyses. Another study by Annor, Clayton [44] conducted on the same 2015 sample showed that students reporting SO discordance were at a higher risk of SAs.

The Youth Risk Behavior Surveillance System (YRBSS) [45] monitored six categories of priority health behaviours among youths and young adults. One of them included behaviors that contribute to injuries and violence, such as SA/NSSI. The database revealed that 1229 participants self-identified as LGBTQ. LGBTQ teenagers had higher rates of suicidal acts. According to the YRBSS, in 2015, 42.8\% considered suicide, 38.2\% planned suicide, $29.4 \%$ attempted suicide at least once and 9.4\% were involved in a SA that ended in an injury requiring medical help. Additionally, females included in this survey reported higher rates of sadness or hopelessness than males $(66.5 \% / 43.9 \%)$. Suicidal thoughts, SP, SAs and injurious SAs - all appeared in higher rates among females than among males $(66.5 \% / 43.9 \%, 42.0 \% / 27.0 \%$, $32.8 \% / 19.4 \%$ and $10.3 \% / 7.0 \%$; respectively).

A co-twin control study in Sweden [46] demonstrated that genetic and environmental factors as well as symptoms of psychopathology (shared by twins) were partially associated with SO and adolescent SAs/NSSIs. The results be- fore adjustments indicated that the odds for SA/NSSI in SGM groups were twice as high as in heterosexual groups. SA/NSSI (Odds Ratio (OR), 2.02 (1.6-2.5)), NSSI (OR, 2.02 (1.6-2.5)), and SA (OR, 1.89 (1.29-2.78)). After adjustment the odds were-NSSI (OR, 1.55 (1.11-2.16)), meaning that SO increases the risk of SA/NSSI only mildly, but genetic and environmental factors have a significant effect.

In a large-scale study of 1896 participants aged 18 30, 3 suicide-related outcomes were examined: number of SAs in the previous year, number of SI incidents in the previous year, and a composite measure of completed suicide risk. Among the factors that contributed to SI were age, non-heterosexual identity, gender-related negative self-perception, and lack of family support, while SAs were related to age, male identity, SO-based victimization, and lack of support from friends. Depression symptoms and victimization related to gender predicted each outcome independently. Positive suicide risk assessment was associated with pansexual identity and negative self-concepts [47].

Studies (98\%) consistently showed a higher rate of SAs among SGMs, both in general and across subgroup analyses by gender and different dimensions of SO (identity, behavior, attraction). This applied to lifetime SAs [4862], SAs in the past 6 or 12 months [9,51,54,57,58,61,6367]; or in the previous five years [68]. The majority of the effects $(58 \%)$ were strong.

\subsection{Adolescents}

Most studies (98\%) report that SGM teenagers demonstrate higher rates of lifetime SAs [61,69-73], previous year SAs [11,61,74-89] and SAs over a 6-month period [75]. One study reports overall higher rates of SAs among SGM teenagers in British Columbia [90]. Contradictory findings were rare ( $2 \%$ of the articles) and were relevant only to specific subgroups $[60,81,83,85]$. The effects were mostly strong ( $47 \%$ of the studies) or medium sized $(33 \%$ of the studies). In the Add Health wave studies (Waves I, II, III and IV), young SGM individuals displayed higher rates of SAs over the previous year [91-93].

\subsection{Subgroup differences}

According to most publications included in this study, bisexual individuals showed the largest effects among SGM Gay and lesbian individual showed smaller effects [48,63, 78,81]. Yet, bisexual adolescents only had an elevated risk rate in the "behavior" SO subgroup, however not in the “identity" subgroup [80,86,87].

\section{Discussion}

Literature consistently reports higher rates of SAs in SGM: in all age groups, and regions, regardless of natal sex, gender identity or SO [8,9]. The majority of the effects were strong. In subgroup analysis, most studies found the strongest effects for bisexual people followed by ho- 
mosexual/lesbian/gay people and the weakest effects were found in queer individuals. The differences between bisexual and homosexual people with regard to SO were less evident or nonexistent. In comparison to heterosexual population, gay men tend to have higher odds ratio of SA than lesbian women, according to most studies.

The so-called "gender paradox in suicide" exists in almost every country in the world. Namely, almost everywhere in the world the rates of SI and SA are higher among women, while the rate of death by suicide is higher among men [19]. This narrative review attempts to reveal whether this paradox changes in various SGM and SO subgroups.

A variety of explanations are offered in the literature for the gender paradox in the general populations (e.g., differing access to lethal weapons between males and females, differences in seeking help and in cultural expectations, etc.). The current study did not address these issues, instead it focused on the differences regarding suicidal behavior, among the various LGBTQ communities.

In most studies on suicide, bisexual males' and females' populations were not found to differ in their suicide rates. However, there is evidence that depression and anxiety rates vary by gender when comparing bisexual with heterosexual, or with lesbian/gay populations. Both gay/lesbian and bisexual individuals demonstrated higher rates of depression and anxiety, but among natal women the difference between bisexual and lesbian/gay was greater [27]. It is worth mentioning, that in most countries, risk factors and pattern of transition from SI to SA remain quite similar [94].

According to a recent meta-analysis investigating the differences in rates of SI and SA between bisexual and heterosexual populations, gender/sex was the most consistent and vital moderator [27]. While suicide literature mentions a gender/sex paradox [19], no explanation is provided on how gender/sex moderates the association between bisexuality and suicide-related results. According to the above mentioned meta-analysis, bisexual women (OR, 1.48-1.95), are at greater risk of suicide than bisexual men (OR, 1.00-1.48). Based on the assumption that the moderating effect is real, a complicated interaction is suggested between gender, sexuality, and experiences of intimacy [95-97].

Within the gay community, bisexual people receive less assistance and support [95,97]. Bisexual women in particular, feel more neglected and stigmatized. According to Weiss [97], while bisexual women activists did not hesitate to support lesbian feminist movements some members this community regarded bisexual women's association with men as betrayal of the lesbian cause. Meanwhile it seems that bisexual men's relationships with women were not judged in the same manner. It thus seems that due to their sexual identity, bisexual women are likely to experience greater political marginalization from the LGBTQ community than bisexual men. However, to the best of the current authors' knowledge possible differences in the support of LGBTQ communities of bisexual women and bisexual men have not been investigated so far.

Bisexual women and men may differ with regard to patterns and effects of partner status [98]. While bisexual men and women may be partnered with both genders [20], sexism and associated male privileges push women, more than men, to be partnered with the opposite gender. Studies have shown that among heterosexual people, men benefit more emotionally from marriage than women [99,100]. A recent study of gay and bisexual men found that the odds of a recent SA were significantly lower for bisexual men partnered with women than for those partnered with men (AOR $0.22,95 \%$ Confidence Interval (CI) 0.07, 0.68) [101].

Based on gender/sex-related differences in the formation of sexual identities [20], it is likely that age, gender, and sexuality cross play in determining suicide risk. According to gender/sex-stratified analyses of the Canadian Community Health Survey, bisexual women and lesbian/gay men differ considerably in mean ages of recent SA: 34.3 years (95\% CI 32.6, 36.0) for bisexual women versus 40.0 years $(38.0,41.9)$ for lesbian women; 39.3 years $(36.5,42.1)$ for bisexual men versus 39.9 years $(38.4,41.4)$ for gay men $[102,103]$. Younger age is associated with higher risk of SI and SAin heterosexual as well as homosexual or bisexual individuals [94].

\subsection{Non-suicidal self-injury (NSSI)}

Almost all studies found an association between SGM and NSSI, as well as showing that being a female constitutes a significant moderator. Namely, women are more likely to self-harm. Thus one may conclude that lesbian women are more likely to revert to NSSI than gay men. According to the earlier mentioned differences between the combined SGM groups and transgender individuals it can be assumed that gay men are at significantly lower risk for NSSI than bisexual and transgender individuals. However, direct evaluation is required to verify these assumptions.

According to SGM stress models [38], having to cope with the negative experiences unique to these minorities such as homophobia, stigma and discrimination, may impact their mental health and result in behaviors like NSSI.

\subsection{Factors that reduce the risk of suicidal behavior}

The literature on factors that protect against suicidality in the LGBTQ community is scarce. Eisenberg and Resnick [104] investigated data from the 2004 Minnesota Student Survey ( $\mathrm{N}=21,927$, of whom 2255 were LGBTQ). The authors identified three protective factors: family connectedness (perceived care of one's parents for one's well-being), caring adults (perceived respect and care of teachers and other meaningful adults), and school safety (feeling safe in school) [104-106]. A stable intimate relationship may also decrease suicide risk [9]. 
The social environment is critical for suicide prevention. A study of 11 th grade students conducted in 34 Oregon counties [78] revealed a $20 \%$ higher risk for SAs among LGBTQ students in counties that did not sanction an environment supportive of LGBTQ. Such negative environment includes low proportion of same-sex couples, absence of gay-straight alliance programs in schools, and lack of school policies against LGB discrimination and bullying. Raifman [107] showed that in US states with established same-sex marriage policies the reported rate of SAs among high school students decreased by $7 \%$.

A meta-analysis that examined depression and anxiety rates in bisexual and gay/lesbian populations, demonstrated effect modification according to gender. It showed that bisexual women and men reported higher levels of depression and anxiety than lesbian women and gay men, with greater difference between bisexual women and lesbian women [27].

\subsection{Transgender and non-conforming (TGNC) people}

Transgender individuals are at a higher risk for suicide and self-harm than cisgenders. In a large 2016 sample of 9th and 11th grade students in Minnesota $(\mathrm{N}=81,885)$, the authors compared [105] four high-risk behaviours and experiences and four protective factors in cisgender students and transgender/gender-non-conforming (TGNC) students. Students who identified as TGNC ( $=2168,2.7 \% ; 3.6 \%$ natal females and $1.7 \%$ natal males) were from a variety of race and ethnicity communities, ranging from $2.2 \%$ white students to $8.6 \%$ Pacific Islanders. TGNC individuals were more involved than cisgenders in risk behaviours such as substance abuse (cigarettes, alcohol, and marijuana), sex with multiple -partners, unprotected sex, and sex under the influence of drugs. TGNC youths reported more incidents of being bullied, higher rates of depressive symptoms (57.9\%, cisgenders $21.3 \%$ ), more incidents of self-harm in the previous year $(54.8 \%$, cisgenders $14.4 \%)$ and more persistent SI $(61.3 \%$, cisgender $20.0 \%)$ and SAs $(31.0 \%$, cisgender $7.1 \%$ ).

Sex reassignment surgery, previously believed to be a contributing factor to suicide, is currently considered as protective for transgender individuals, decreasing the risk from the pre-surgery $20 \%$ to a much lower post-surgery rate $(0.5-1.9 \%)$. Within the TGNC group, risk and protective factors differed between the natal sexes. Natal males demonstrated higher rates of substance abuse and being physically bullied, while natal females reported higher rates of emotional distress, mental health problems and experiencing non-physical bullying.

Possessing gender-concordant identity documents (featuring their chosen gender and name) is associated with lower rates of severe psychological distress, SI, and SP (but not a lower rate of SA/NSSI) [110].

\section{Limitations}

This review has the limitations that are inherent to a narrative review. It's conclusions must be taken carefully, results should be repeated, preferably in a systematic review, and longitudinal studies should be performed. This study is based on studies from the years 1970-2021. In the last 50 years the association between being LGBTQ and suicide has been researched dramatically more than before. Social norms regarding LGBTQ people and attitudes towards them have changed dramatically too. Thus, terms are sometimes unclear or changed their meaning over time, as have the medical approaches towards LGBTQ individuals. All these changes are reflected in the medical literature, both in research and in textbooks like the DSM and others.

\section{Conclusions}

The so-called "gender paradox in suicide" known from studies of cisgender, heterosexual populations does not hold true in SGM groups. There are however differences among the various SO and sexual identity groups with regard to suicidality, but these differences are not clear cut due to a scarcity of research.

The junction between gender and sexual identity is often unpredictable with regard to suicidal behavior. The many facets that are still unclear include the association of suicidal behavior with aspects of gender/sex, partners and their gender, bisexuality in all its variations, transgender individuals before and after sex-reassignment surgery, etc. These need to be understood before any serious attempt can be made to reduce suicidal behavior among SGMs.

Future research, particularly of a longitudinal nature, on sex and gender identity related differences regarding suicidal behavior is warranted and highly necessary.

\section{Abbreviations}

LGBTQ, Lesbian, Gay, Bisexual, Transgender, and Queer; TGNC, Transgender and Gender-Non-Conforming; SGM, Sexual and Gender Minorities; SO, Sexual Orientation; SI, Suicidal Ideation; SA, Suicide Attempt; SP, Suicide Plan; NSSI, Non-Suicidal Self- Injury.

\section{Author contributions}

AK and LTL conceived the idea, planned and designed the study. Both authors conducted the research, searched related publications, summarized the results and contributed to the interpretation of the results. Drafting of the manuscript was done by AK with guidance from LTL. Both authors reviewed the manuscript critically. Both authors read and approved the final version of the manuscript and gave their approval for its submission.

\section{Ethics approval and consent to participate}




\section{Acknowledgment}

Not applicable.

\section{Funding}

This research received no external funding.

\section{Conflict of interest}

The authors declare no conflict of interest.

\section{References}

[1] Zalsman G, Hawton K, Wasserman D, van Heeringen K, Arensman E, Sarchiapone M, et al. Suicide prevention strategies revisited: 10-year systematic review. The Lancet Psychiatry. 2016; 3: 646-659.

[2] Turecki G, Brent DA. Suicide and suicidal behaviour. Lancet. 2016; 387: 1227-1239.

[3] Aranmolate R, Bogan DR, Hoard T, Mawson, AR. Suicide risk factors among LGBTQ youth. JSM Schizophrenia. 2017; 2: 1011.

[4] World Health Organization. Suicides in the world: Global Health Estimates (No. WHO/MSD/MER/19.3). 2019. Available at: https://apps.who.int/iris/bitstream/handle/10665/326948/ WHO-MSD-MER-19.3-eng.pdf? sequence $=1 \&$ is Allowed $=\mathrm{y}$ (Accessed: 2 September 2021)

[5] Hottes TS, Bogaert L, Rhodes AE, Brennan DJ, Gesink D. Lifetime Prevalence of Suicide Attempts among Sexual Minority Adults by Study Sampling Strategies: a Systematic Review and Meta-Analysis. American Journal of Public Health. 2016; 106: e1-e12.

[6] King M, Semlyen J, Tai SS, Killaspy H, Osborn D, Popelyuk $\mathrm{D}$, et al. A systematic review of mental disorder, suicide, and deliberate self harm in lesbian, gay and bisexual people. BMC Psychiatry. 2008; 8: 70.

[7] Marshal MP, Dietz LJ, Friedman MS, Stall R, Smith HA, McGinley J, et al. Suicidality and Depression Disparities between Sexual Minority and Heterosexual Youth: a MetaAnalytic Review. Journal of Adolescent Health. 2011; 49: 115123.

[8] Plöderl M, Tremblay P. Mental health of sexual minorities. a systematic review. International Review of Psychiatry. 2016; 27 : 367-385.

[9] Haas AP, Eliason M, Mays VM, Mathy RM, Cochran SD, D'Augelli AR, et al. Suicide and suicide risk in lesbian, gay, bisexual, and transgender populations: review and recommendations. Journal of Homosexuality. 2011; 58: 10-51.

[10] Conron KJ, Goldberg SK, Halpern CT. Sexual orientation and sex differences in socioeconomic status: a population-based investigation in the National Longitudinal Study of Adolescent to Adult Health. Journal of Epidemiology and Community Health. 2018; 72: 1016-1026.

[11] Garofalo R, Wolf RC, Wissow LS, Woods ER, Goodman E. Sexual orientation and risk of suicide attempts among a representative sample of youth. Archives of Pediatrics \& Adolescent Medicine. 1999; 153: 487-493.

[12] Pakula B, Shoveller J, Ratner PA, Carpiano R. Prevalence and Co-Occurrence of Heavy Drinking and Anxiety and Mood Disorders among Gay, Lesbian, Bisexual, and Heterosexual Canadians. American Journal of Public Health. 2016; 106: 1042-1048.

[13] Obedin-Maliver J, Goldsmith ES, Stewart L, White W, Tran $\mathrm{E}$, Brenman $\mathrm{S}$, et al. Lesbian, gay, bisexual, and transgenderrelated content in undergraduate medical education. Journal of the American Medical Association. 2011; 306: 971-977.

[14] Batejan KL, Jarvi SM, Swenson LP. Sexual orientation and non- suicidal self-injury: a meta-analytic review. Archives of Suicide Research. 2015; 19: 131-150.

[15] Jackman K, Honig J, Bockting W. Nonsuicidal self-injury among lesbian, gay, bisexual and transgender populations: an integrative review. Journal of Clinical Nursing. 2016; 25: 34383453.

[16] O’Brien KHM, Liu RT, Putney J, Burke TA, Aguinaldo L, Smalley KB, et al. Suicide and non-suicidal self-injury. LGBT Health: Meeting the Health Needs of Gender and Sexual Minorities (pp. 181-198). Springer: New York. 2017.

[17] Liu RT, Sheehan AE, Walsh RFL, Sanzari CM, Cheek SM, Hernandez EM. Prevalence and correlates of non-suicidal selfinjury among lesbian, gay, bisexual, and transgender individuals: a systematic review and meta-analysis. Clinical Psychology Review. 2019; 74: 101783

[18] Canetto SS, Sakinofsky I. The gender paradox in suicide. Suicide \& Life-Threatening Behavior. 1998; 28: 1-23.

[19] Rhodes AE, Boyle MH, Bridge JA, Sinyor M, Links PS, Tonmyr $\mathrm{L}$, et al. Antecedents and sex/gender differences in youth suicidal behavior. World Journal of Psychiatry. 2014; 4: 120-132.

[20] Herek GM, Norton AT, Allen TJ, Sims CL. Demographic, Psychological, and Social Characteristics of Self-Identified Lesbian, Gay, and Bisexual Adults in a us Probability Sample. Sexuality Research \& Social Policy. 2010; 7: 176-200.

[21] Katz-Wise SL, Hyde JS. Victimization experiences of lesbian, gay, and bisexual individuals: a meta-analysis. Journal of Sex Research. 2012; 49: 142-167.

[22] Savin-Williams RC, Diamond LM. Sexual identity trajectories among sexual-minority youths: gender comparisons. Archives of Sexual Behavior. 2000; 29: 607-627.

[23] Diamond LM, Butterworth M. Questioning Gender and Sexual Identity: Dynamic Links over Time. Sex Roles. 2008; 59: 365376.

[24] Katz-Wise SL. Sexual fluidity in young adult women and men associations with sexual orientation and sexual identity development. Psychology \& Sexuality. 2015; 6: 189-208.

[25] Veenstra G. Race, gender, class, and sexual orientation: intersecting axes of inequality and self-rated health in Canada. International Journal for Equity in Health. 2011; 10: 3.

[26] van Anders SM. Beyond Sexual Orientation: Integrating Gender/Sex and Diverse Sexualities via Sexual Configurations Theory. Archives of Sexual Behavior. 2015; 44: 1177-1213.

[27] Salway T, Ross LE, Fehr CP, Burley J, Asadi S, Hawkins B, et $a l$. A Systematic Review and Meta-Analysis of Disparities in the Prevalence of Suicide Ideation and Attempt among Bisexual Populations. Archives of Sexual Behavior. 2019; 48: 89-111.

[28] Haas AP, Eliason M, Mays VM, Mathy RM, Cochran SD, D'Augelli AR, et al. Suicide and suicide risk in lesbian, gay, bisexual, and transgender populations: review and recommendations. Journal of Homosexuality. 2010; 58: 10-51.

[29] Qin P, Agerbo E, Mortensen PB. Suicide risk in relation to socioeconomic, demographic, psychiatric, and familial factors: a national register-based study of all suicides in Denmark, 19811997. The American Journal of Psychiatry. 2003; 160: 765-772.

[30] Mathy RM, Cochran SD, Olsen J, Mays VM. The association between relationship markers of sexual orientation and suicide: Denmark, 1990-2001. Social Psychiatry and Psychiatric Epidemiology. 2011; 46: 111-117.

[31] Frisch M, Simonsen J. Marriage, cohabitation and mortality in Denmark: national cohort study of 6.5 million persons followed for up to three decades (1982-2011). International Journal of Epidemiology. 2013; 42: 559-578.

[32] Robinson J, Cox G, Malone A, Williamson M, Baldwin G, Fletcher K, et al. A systematic review of school-based interventions aimed at preventing, treating, and responding to suiciderelated behavior in young people. Crisis. 2013; 34: 164-182.

[33] Plöderl M, Wagenmakers E, Tremblay P, Ramsay R, Kralovec K, 
Fartacek C, et al. Suicide risk and sexual orientation: a critical review. Archives of Sexual Behavior. 2013; 42: 715-727.

[34] Cochran SD, Mays VM. Mortality risks among persons reporting same-sex sexual partners: evidence from the 2008 General Social Survey-National Death Index data set. American Journal of Public Health. 2015; 105: 358-364.

[35] Shaffer D, Fisher P, Hicks RH, Parides M, Gould M. Sexual orientation in adolescents who commit suicide. Suicide \& LifeThreatening Behavior. 1995; 25 Suppl: 64-71.

[36] Renaud J, Berlim MT, Begolli M, McGirr A, Turecki G. Sexual orientation and gender identity in youth suicide victims: an exploratory study. Canadian Journal of Psychiatry. Revue Canadienne De Psychiatrie. 2010; 55: 29-34.

[37] Lyons BH, Walters ML, Jack SPD, Petrosky E, Blair JM, IveyStephenson AZ. Suicides among Lesbian and Gay Male Individuals: Findings from the National Violent Death Reporting System. American Journal of Preventive Medicine. 2019; 56: 512-521.

[38] Meyer IH. Prejudice, social stress, and mental health in lesbian, gay, and bisexual populations: conceptual issues and research evidence. Psychological Bulletin. 2003; 129: 674-697.

[39] Lick DJ, Durso LE, Johnson KL. Minority Stress and Physical Health among Sexual Minorities. Perspectives on Psychological Science. 2013; 8: 521-548.

[40] Office of the Surgeon General (US); National Action Alliance for Suicide Prevention (US). 2012 National Strategy for Suicide Prevention: Goals and Objectives for Action. A Report of the U.S. Surgeon General and of the National Action Alliance for Suicide Prevention. US Department of Health \& Human Services (US): Washington, DC. 2012.

[41] Narang P, Sarai SK, Aldrin S, Lippmann S. Suicide Among Transgender and Gender-Nonconforming People. The Primary Care Companion for CNS Disorders. 2018; 20: 18nr02273.

[42] Matarazzo BB, Barnes SM, Pease JL, Russell LM, Hanson JE, Soberay KA, et al. Suicide risk among lesbian, gay, bisexual, and transgender military personnel and veterans: what does the literature tell us? Suicide \& Life-Threatening Behavior. 2014; 44: 200-217.

[43] Caputi TL, Smith D, Ayers JW. Suicide Risk Behaviors among Sexual Minority Adolescents in the United States, 2015. Journal of the American Medical Association. 2017; 318: 2349-2351.

[44] Annor FB, Clayton HB, Gilbert LK, Ivey-Stephenson AZ, Irving SM, David-Ferdon C, et al. Sexual Orientation Discordance and Nonfatal Suicidal Behaviors in US High School Students. American Journal of Preventive Medicine. 2018; 54: 530-538.

[45] Kann L, McManus T, Harris WA, Shanklin SL, Flint KH, Queen B, et al. Youth Risk Behavior Surveillance - United States, 2017. Morbidity and Mortality Weekly Report. Surveillance Summaries. 2018; 67: 1-114.

[46] O’Reilly LM, Pettersson E, Donahue K, Quinn PD, Klonsky ED, Lundström $\mathrm{S}$, et al. Sexual orientation and adolescent suicide attempt and self-harm: a co-twin control study. Journal of Child Psychology and Psychiatry. 2021; 62: 834-841.

[47] Kuper LE, Adams N, Mustanski BS. Exploring Cross-Sectional Predictors of Suicide Ideation, Attempt, and Risk in a Large Online Sample of Transgender and Gender Nonconforming Youth and Young Adults. LGBT Health. 2018; 5: 391-400.

[48] Bagley C, Tremblay P. Suicidal behaviors in homosexual and bisexual males. Crisis. 1997; 18: 24-34.

[49] Chakraborty A, McManus S, Brugha TS, Bebbington P, King M. Mental health of the non-heterosexual population of England. The British Journal of Psychiatry. 2011; 198: 143-148.

[50] Cochran SD, Mays VM. Lifetime prevalence of suicide symptoms and affective disorders among men reporting same-sex sexual partners: results from NHANES III. American Journal of Public Health. 2000; 90: 573-578.
[51] Cochran SD, Mays VM, Alegria M, Ortega AN, Takeuchi D. Mental health and substance use disorders among Latino and Asian American lesbian, gay, and bisexual adults. Journal of Consulting and Clinical Psychology. 2007; 75: 785-794.

[52] de Graaf R, Sandfort TGM, ten Have M. Suicidality and sexual orientation: differences between men and women in a general population-based sample from the Netherlands. Archives of Sexual Behavior. 2006; 35: 253-262.

[53] Fergusson DM, Horwood LJ, Beautrais AL. Is sexual orientation related to mental health problems and suicidality in young people? Archives of General Psychiatry. 1999; 56: 876-880.

[54] Gilman SE, Cochran SD, Mays VM, Hughes M, Ostrow D, Kessler RC. Risk of psychiatric disorders among individuals reporting same-sex sexual partners in the National Comorbidity Survey. American Journal of Public Health. 2001; 91: 933-939.

[55] Herrell R, Goldberg J, True WR, Ramakrishnan V, Lyons M, Eisen S, et al. Sexual orientation and suicidality: a co-twin control study in adult men. Archives of General Psychiatry. 1999; 56: $867-874$.

[56] Husky MM, Guignard R, Beck F, Michel G. Risk behaviors, suicidal ideation and suicide attempts in a nationally representative French sample. Journal of Affective Disorders. 2013; 151: 1059-1065.

[57] Lhomond B, Saurel-Cubizolles M. Violence against women and suicide risk: the neglected impact of same-sex sexual behaviour. Social Science \& Medicine. 2006; 62: 2002-2013.

[58] Oswalt SB, Wyatt TJ. Sexual Orientation and Differences in Mental Health, Stress, and Academic Performance in a National Sample of U.S. College Students. Journal of Homosexuality. 2011; 58: 1255-1280.

[59] Pelts MD, Albright DL. An Exploratory Study of Student Service Members/Veterans' Mental Health Characteristics by Sexual Orientation. Journal of American College Health. 2015; 63: 508-512.

[60] Skegg K, Nada-Raja S, Dickson N, Paul C, Williams S. Sexual orientation and self-harm in men and women. The American Journal of Psychiatry. 2003; 160: 541-546.

[61] Wang L, Chiang S, Su L, Lin S, Chen C. Factors associated with drug-related psychiatric disorders and suicide attempts among illicit drug users in Taiwan. Substance Use \& Misuse. 2012; 47: $1185-1188$.

[62] Wichstrøm L, Hegna K. Sexual orientation and suicide attempt: a longitudinal study of the general Norwegian adolescent population. Journal of Abnormal Psychology. 2003; 112: 144-151.

[63] Blosnich J, Bossarte R. Drivers of disparity: differences in socially based risk factors of self-injurious and suicidal behaviors among sexual minority college students. Journal of American College Health. 2012; 60: 141-149.

[64] Kerr DL, Santurri L, Peters P. A comparison of lesbian, bisexual, and heterosexual college undergraduate women on selected mental health issues. Journal of American College Health. 2013; 61: 185-194.

[65] Lian Q, Zuo X, Lou C, Gao E, Cheng Y. Sexual orientation and risk factors for suicidal ideation and suicide attempts: a multicentre cross-sectional study in three Asian cities. Journal of Epidemiology. 2015; 25: 155-161.

[66] McNair R, Kavanagh A, Agius P, Tong B. The mental health status of young adult and mid-life non-heterosexual Australian women. Australian and New Zealand Journal of Public Health. 2005; 29: 265-271.

[67] Reed E, Prado G, Matsumoto A, Amaro H. Alcohol and drug use and related consequences among gay, lesbian and bisexual college students: Role of experiencing violence, feeling safe on campus, and perceived stress. Addictive Behaviors. 2010; 35: 168-171.

[68] Fergusson D, Doucette S, Glass KC, Shapiro S, Healy D, Hebert 
$\mathrm{P}$, et al. Association between suicide attempts and selective serotonin reuptake inhibitors: systematic review of randomised controlled trials. British Medical Journal. 2005; 330: 396.

[69] Button DM, O'Connell DJ, Gealt R. Sexual minority youth victimization and social support: the intersection of sexuality, gender, race, and victimization. Journal of Homosexuality. 2012; 59: $18-43$.

[70] McMahon EM, Reulbach U, Keeley H, Perry IJ, Arensman E. Reprint of: bullying victimisation, self harm and associated factors in Irish adolescent boys. Social Science \& Medicine. 2012; 74: 490-497.

[71] O'Connor RC, Rasmussen S, Hawton K. Predicting Deliberate Self-Harm in Adolescents: a Six Month Prospective Study. Suicide and Life-Threatening Behavior. 2009; 39: 364-375.

[72] O'Connor RC, Nock MK. The psychology of suicidal behaviour. The Lancet. Psychiatry. 2014; 1: 73-85.

[73] Remafedi G, French S, Story M, Resnick MD, Blum R. The relationship between suicide risk and sexual orientation: results of a population-based study. American Journal of Public Health. 1998; 88: 57-60.

[74] Almeida J, Johnson RM, Corliss HL, Molnar BE, Azrael D. Emotional Distress among LGBT Youth: the Influence of Perceived Discrimination Based on Sexual Orientation. Journal of Youth and Adolescence. 2009; 38: 1001-1014.

[75] Bostwick WB, Meyer I, Aranda F, Russell S, Hughes T, Birkett $\mathrm{M}$, et al. Mental health and suicidality among racially/ethnically diverse sexual minority youths. American Journal of Public Health. 2014; 104: 1129-1136.

[76] DuRant RH, Krowchuk DP, Sinal SH. Victimization, use of violence, and drug use at school among male adolescents who engage in same-sex sexual behavior. the Journal of Pediatrics. 1998; 133: 113-118.

[77] Faulkner AH, Cranston K. Correlates of same-sex sexual behavior in a random sample of Massachusetts high school students. American Journal of Public Health. 1998; 88: 262-266.

[78] Hatzenbuehler ML. The social environment and suicide attempts in lesbian, gay, and bisexual youth. Pediatrics. 2011; 127: 896903.

[79] Hatzenbuehler ML, Bellatorre A, Lee Y, Finch BK, Muennig P, Fiscella K. Structural stigma and all-cause mortality in sexual minority populations. Social Science \& Medicine. 2014; 103: 33-41.

[80] Kann L, Olsen EO, McManus T, Kinchen S, Chyen D, Harris WA, et al. Sexual identity, sex of sexual contacts, and healthrisk behaviors among students in grades 9-12-youth risk behavior surveillance, selected sites, United States, 2001-2009. Morbidity and Mortality Weekly Report. Surveillance Summaries. 2011; 60: 1-133.

[81] Olshen E, McVeigh KH, Wunsch-Hitzig RA, Rickert VI. Dating violence, sexual assault, and suicide attempts among urban teenagers. Archives of Pediatrics \& Adolescent Medicine. 2007; 161: 539-545.

[82] Mustanski B, Birkett M, Greene GJ, Rosario M, Bostwick W, Everett BG. The Association between Sexual Orientation Identity and Behavior across Race/Ethnicity, Sex, and Age in a Probability Sample of High School Students. American Journal of Public Health. 2014; 104: 237-244.

[83] Saewyc EM, Skay CL, Hynds P, Pettingell S, Bearinger LH, Resnick MD, et al. Suicidal Ideation and Attempts in North American School-Based Surveys: are Bisexual Youth at Increasing Risk? Journal of LGBT Health Research. 2007; 3: 25-36.

[84] Taliaferro LA, Muehlenkamp JJ. Risk and Protective Factors that Distinguish Adolescents who Attempt Suicide from those who only Consider Suicide in the Past Year. Suicide and LifeThreatening Behavior. 2014; 44: 6-22.

[85] Zhao Y, Montoro R, Igartua K, Thombs BD. Suicidal Ideation and Attempt among Adolescents Reporting "Unsure" Sexual Identity or Heterosexual Identity Plus same-Sex Attraction or Behavior: Forgotten Groups? Journal of the American Academy of Child \& Adolescent Psychiatry. 2010; 49: 104 113.

[86] Stone DM, Luo F, Ouyang L, Lippy C, Hertz MF, Crosby AE. Sexual orientation and suicide ideation, plans, attempts, and medically serious attempts: evidence from local Youth Risk Behavior Surveys, 2001-2009. American Journal of Public Health. 2014; 104: 262-271.

[87] Stone DM, Luo F, Lippy C, McIntosh WL. The Role of Social Connectedness and Sexual Orientation in the Prevention of Youth Suicide Ideation and Attempts among Sexually Active Adolescents. Suicide \& Life-Threatening Behavior. 2015; 45: 415-430.

[88] Pinhey TK, Millman SR. Asian/Pacific Islander adolescent sexual orientation and suicide risk in Guam. American Journal of Public Health. 2004; 94: 1204-1206.

[89] Seil KS, Desai MM, Smith MV. Sexual orientation, adult connectedness, substance use, and mental health outcomes among adolescents: findings from the 2009 New York City Youth Risk Behavior Survey. American Journal of Public Health. 2014; 104: 1950-1956.

[90] Lampinen TM, McGhee D, Martin I. Increased risk of "club" drug use among gay and bisexual high school students in British Columbia. Journal of Adolescent Health. 2006; 38: 458-461.

[91] Russell ST, Joyner K. Adolescent sexual orientation and suicide risk: evidence from a national study. American Journal of Public Health. 2001; 91: 1276-1281.

[92] Williams KA, Chapman MV. Comparing health and mental health needs, service use, and barriers to services among sexual minority youths and their peers. Health \& Social Work. 2011; 36: 197-206.

[93] Fried LE, Williams S, Cabral H, Hacker K. Differences in risk factors for suicide attempts among 9th and 11th grade youth: a longitudinal perspective. The Journal of School Nursing. 2013; 29: $113-122$

[94] Nock MK, Borges G, Bromet EJ, Alonso J, Angermeyer M, Beautrais A, et al. Cross-national prevalence and risk factors for suicidal ideation, plans and attempts. The British Journal of Psychiatry. 2008; 192: 98-105.

[95] Persson TJ, Pfaus JG. Bisexuality and Mental Health: Future Research Directions. Journal of Bisexuality. 2015; 15: 82-98.

[96] Schick V, Dodge B. Introduction to the Special Issue: Bisexual Health: Unpacking the Paradox. Journal of Bisexuality. 2012; 12: $161-167$.

[97] Weiss JT. GL vs. BT: The archaeology of biphobia and transphobia within the US gay and lesbian community. Journal of Bisexuality. 2003; 3: 25-55.

[98] Dyar C, Feinstein BA, Zimmerman AR, Newcomb ME, Mustanski B, Whitton SW. Dimensions of Sexual Orientation and Rates of Intimate Partner Violence among Young Sexual Minority Individuals Assigned Female at Birth: The Role of Perceived Partner Jealousy. Psychology of Violence. 2020; 10: 411-421.

[99] Gove WR. Sex, marital status and suicide. Journal of Health and Social Behavior. 1972; 13: 204-213.

[100] Thomeer MB, Umberson D, Pudrovska T. Marital Processes around Depression: a Gendered and Relational Perspective. Society and Mental Health. 2013; 3: 151-169.

[101] Ferlatte O, Salway T, Hankivsky O, Trussler T, Oliffe JL, Marchand R. Recent Suicide Attempts across Multiple Social Identities among Gay and Bisexual Men: an Intersectionality Analysis. Journal of Homosexuality. 2018; 65: 1507-1526.

[102] Brennan DJ, Ross LE, Dobinson C, Veldhuizen S, Steele LS. Men's sexual orientation and health in Canada. Canadian Journal of Public Health. 2010; 101: 255-258. 
[103] Steele LS, Ross LE, Dobinson C, Veldhuizen S, Tinmouth JM. Women's sexual orientation and health: results from a Canadian population-based survey. Women \& Health. 2009; 49: 353-367.

[104] Eisenberg ME, Resnick MD. Suicidality among gay, lesbian and bisexual youth: the role of protective factors. The Journal of Adolescent Health. 2006; 39: 662-668.

[105] Eisenberg ME, Gower AL, McMorris BJ, Rider GN, Shea G, Coleman E. Risk and Protective Factors in the Lives of Transgender/Gender Nonconforming Adolescents. The Journal of Adolescent Health. 2017; 61: 521-526.

[106] Ryan C, Huebner D, Diaz RM, Sanchez J. Family rejection as a predictor of negative health outcomes in white and Latino lesbian, gay, and bisexual young adults. Pediatrics. 2009; 123 : 346-352.

[107] Raifman J, Moscoe E, Austin SB, McConnell M. Differencein-Differences Analysis of the Association between State same-
Sex Marriage Policies and Adolescent Suicide Attempts. JAMA Pediatrics. 2017; 171: 350-356.

[108] Perez-Brumer A, Day JK, Russell ST, Hatzenbuehler ML. Prevalence and Correlates of Suicidal Ideation among Transgender Youth in California: Findings from a Representative, Population-Based Sample of High School Students. Journal of the American Academy of Child and Adolescent Psychiatry. 2017; 56: 739-746.

[109] Grossman AH, D'Augelli AR. Transgender youth and lifethreatening behaviors. Suicide \& Life-Threatening Behavior. 2007; 37: 527-537.

[110] Scheim AI, Perez-Brumer AG, Bauer GR. Gender-concordant identity documents and mental health among transgender adults in the USA: a cross-sectional study. The Lancet Public Health. 2020; 5: e196-e203. 